\author{
International Journal of Innovative Research in \\ Electrical, Electronics, Instrumentation and Control Engineering
}

Vol. 7, Issue 5, May 2019

\title{
MPPT Based Solar Charge Control
}

\author{
Amit Musale, Raj Raut, Vicky Pawar, Laxman Nadimetla \\ Sinhgad Academy of Engineering
}

\begin{abstract}
There area unit inherent power losses that occur once the star is connected on to a load/battery while not matching their internal impedances that additionally to the non-linear (I-V) operative characteristics of a PV module associated variations in its output power with star isolation and operative temperature; an MPPT charge controller is employed in most alternative energy harvest home systems to make sure most rated power is drawn from the solar battery and delivered to the battery whereas charging it in an exceedingly healthy mode to extend its period of time and for potency functions below variable region conditions.
\end{abstract}

Keywords: PIC18F4550, MPPT, Solar panel

\section{INTRODUCTION}

Renewable energy sources area unit quick turning into another to ancient fossil fuels thanks to their benefits of being clean and inexhaustible primarily. Alternative energy is one in every of the renewable energy sources and though it's a high potential its generation potency (conversion of solar power to electricity) is low with most business PV panels having efficiencies of but half-hour. With this already low power generation max efficiency of star panels it's solely necessary that the utmost power is sourced from that generated by star panels to make sure max efficiency in delivering power to the load to create alternative energy a good various and justify its high installation prices too. Since the I-V characteristics of star panels vary with region conditions like irradiance, additional power may be got out of star panels by direct strategies e.g. star trailing to trace the sun because it moves across the sky or by indirect strategies e.g. most outlet trailing the latter being within the compass of this project. victimization MPPT charge controllers reduces variety the amount the quantity\} of PV modules that require to be put in to get an explicit power by increasing the facility generated from the crucial number of PV modules required to get the facility at max efficiency.

\section{PROPOSED SYSTEM}

Charge controllers aim to supply the proper voltage and current ratings for a chargeable battery by watching and regulation the solar battery output voltage to match the batteries. This output voltage regulation is extremely necessary in battery charging as a result of batteries need a particular charging methodology with numerous voltage and current levels for every specific stage, these charging strategies area unit required to prolong battery life and performance. Some common charge controller protection options to stop battery damage are undercharge and overcharge protection. Undercharge protection entails disconnecting the battery once the charge is simply too low to continue powering connected masses, similarly, the charge controller stops providing energy to the battery once it's absolutely charged to stop overcharge. This can be wherever the charge controller will most of the work .Simple charge controllers disconnect the battery once the battery surpasses a strength and reconnect it once the battery level falls below an explicit planned charge level. Alternative protection options embody protection against over-voltage and utterly exhausting ("deep discharging") battery and regulation charging/discharging rates to battery life and improve its generation. From the higher than it's seen that the gist of a charge controller may be a DC to DC device that converts the solar battery voltage to a voltage appropriate for charging the battery where as protective it. Implementing a DC to DC device instead of a linear regulator (or simply connecting the battery on to the PV panel) ensures significantly higher power potency.

\section{A. Block diagram}

Now a days the most advance solar charge controller available in the market is Maximum Power Point Tracking (MPPT).The MPPT controller is more sophisticated and more expensive. It has many benefits over the sooner charge controller.It is 30 to $40 \%$ more efficient at low temperature. But creating a MPPT charge controller is little bit complicated in compare to PWM charge controller. 


\section{International Journal of Innovative Research in Electrical, Electronics, Instrumentation and Control Engineering}

Vol. 7, Issue 5, May 2019

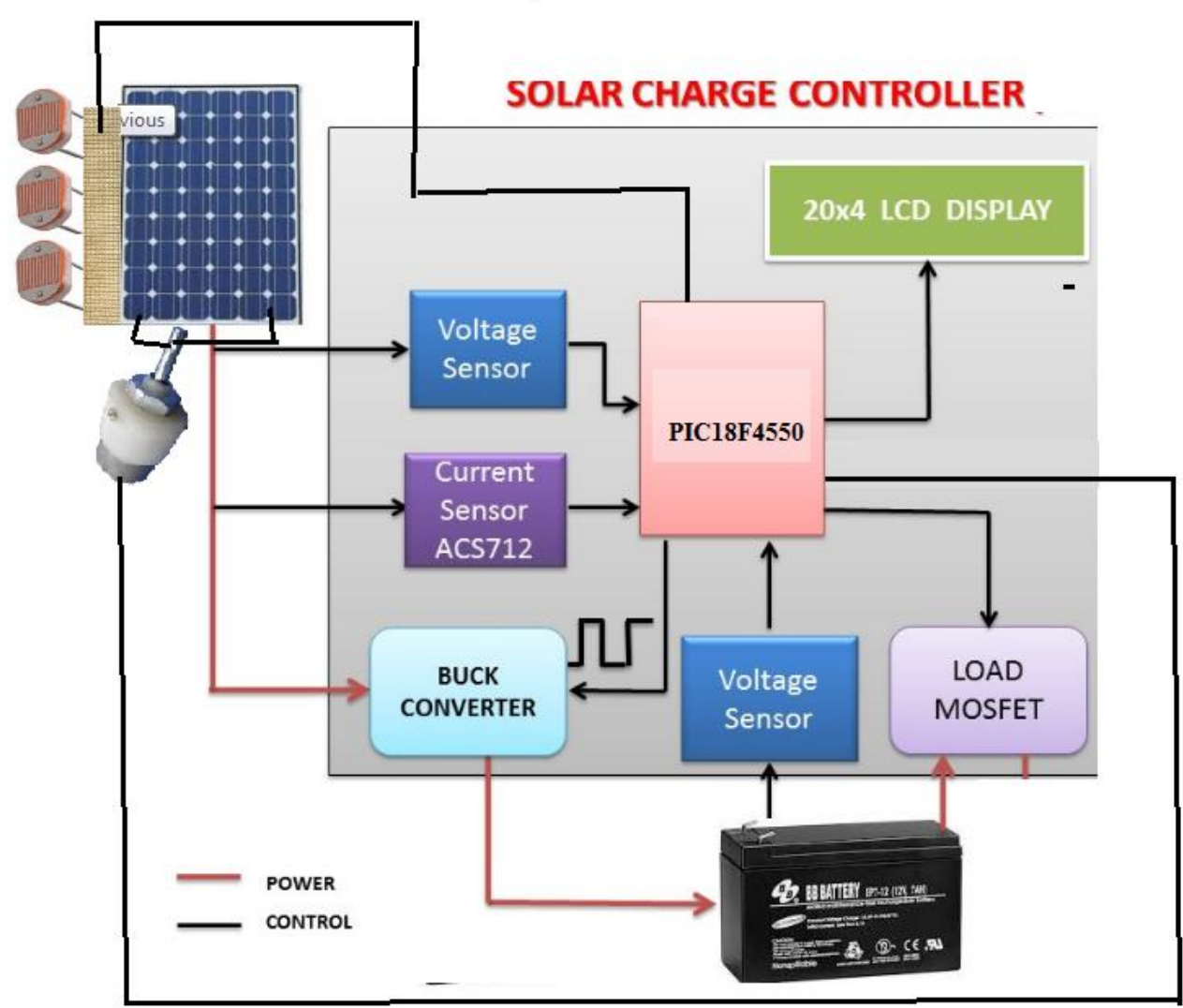

Solar tracking system may be a technique to withdraw most power from solar panels. As we all know solar panels convert solar power into power through electrical \{phenomenon\} phenomenon. Greater the intensity of solar light falls on solar panel, greater output observe at the output of solar panel. So we'd like to develop a such technique that rotate solar panel per following of sun. So we will withdraw most power from our put in PV panels.

MPPT stands for Maximum Power Point Tracking. MPPT charge controllers used for extracting most on the market power from PV module beneath sure conditions. Look at the image shown above. We have seen that the maximum power point (MPP) of a solar panel lies at the knee of the current and voltage curve. A $12 \mathrm{~V}$ solar array isn't very a $12 \mathrm{~V}$ panel in the least. Its very a somewhere in between $12 \mathrm{~V}$ and $21 \mathrm{~V}$ panel betting on what load is connected thereto and the waybright the daylight is. The panel has an indoor resistance that changes dynamically with differing irradiance levels. Solar panels can solely deliver their rated power at one specific voltage and cargo, and this voltage and cargomoves around because the daylight intensity changes.

For example take a solar array rated at one hundred watts, $18 \mathrm{~V}$ at $5.55 \mathrm{amps}$.

The $18 \mathrm{~V}$ at 5.5 amps means that the Solar panel wants to see a load of $18 / 5.5=3.24 \mathrm{ohms}$.

With the other load the panel can deliver but one hundred watts.

So if a static load is connected on to a panel and its resistance is higher or not up to the panels internal resistance at MPP, then the power drawn from the panel are but the utmost on the market.

Taking an easy example say we tend to connected the on top of $100 \mathrm{~W}$ panel on to a $12 \mathrm{~V}$ lead acid battery, the panel voltage would be dragged down near to the load voltage of the battery because the batteries resistance is not up to the panels, but the current stays the same at 5.55 amps. This happens because Solar Panels behave like current sources, so the current is determined by the available sunlight.

Now the power $(\mathrm{P})=\mathrm{V} \times \mathrm{I}=12 \times 5.55=66.6 \mathrm{~W}$.

So the solar array is currently behaving sort of a sixty six watt panel.

This equates to a loss of $100 \mathrm{~W}-66.6 \mathrm{~W}=34 \mathrm{~W}(33.4 \%)$.

This is the explanation for employing a MPPT charge controller rather than a typical charge controller like PWM.

The MPPT controller is consists of a DC -DC converter where the duty cycle is varied to track the Maximum Power Point. 


\section{International Journal of Innovative Research in Electrical, Electronics, Instrumentation and Control Engineering}

Vol. 7, Issue 5, May 2019

A.

BUCK converter

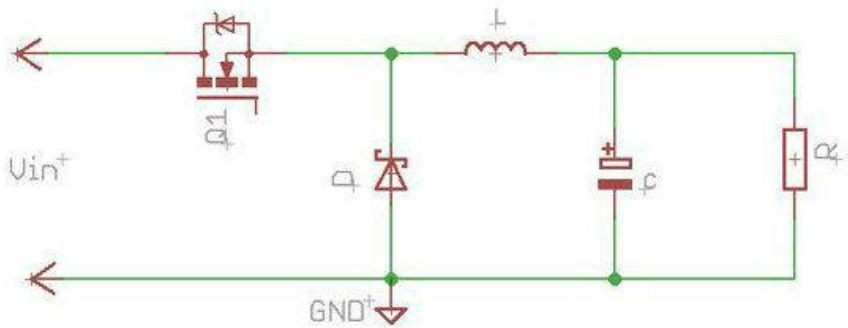

A buck converter is a DC - DC converter in which the output voltage is always lower or same as the input voltage.

\section{When the MOSFET is ON}

When the MOSFET is ON, current flows through the inductor $(\mathrm{L})$, load $(\mathrm{R})$ and the output capacitor $(\mathrm{C})$ as shown in the fig-2. In this condition the diode is reverse biased.So no current flows through it. During the ON state magnetic energy is stored in the inductor and electrical energy is stored in the output capacitor.

\section{When the MOSFET is OFF}

When the MOSFET is off, stored Energy in the Inductor is collapsed and current complete its path through the diode ( forward biased) as shown in fig-3. When stored energy in the inductor vanishes, stored energy in the capacitor is supplied to load to maintain the current.

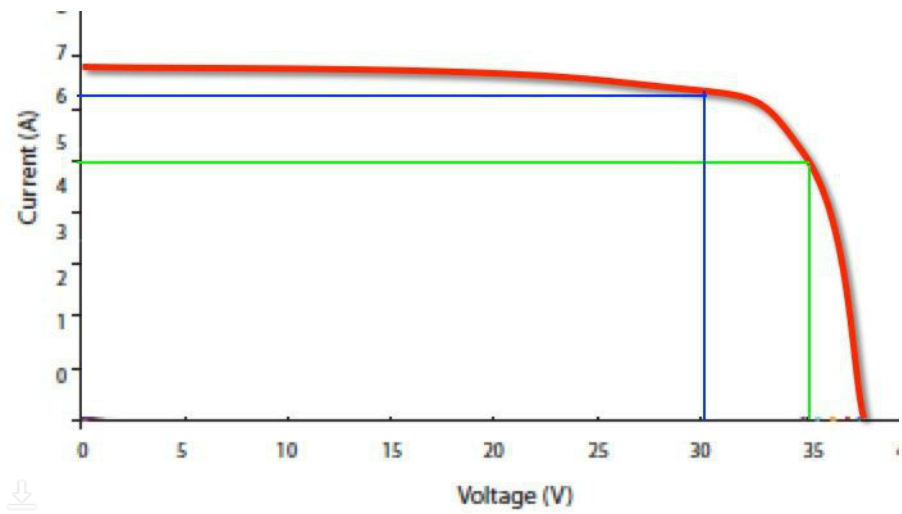

Fig. 1 graph

\section{CONCLUSION}

This project presents circuit of MPPT charge controller. We get a better battery protection from overvoltage using MOSFETs. The results displays by comparator and use of PIC to interface LCD. We are also using solar tracking technique to improve efficiency.

\section{REFERENCES}

[1]. Chaudhary DS, Pawan DK (2013) A Study of Efficient Maximum Power Point Tracking Controlling Methods for Photovoltaic System. International Journal of Advanced Research in Computer Science and Software Engineering 3: 215-219.

[2]. Digrawal A (2013) Simulation Study of Photovoltaic System with MPPT Algorithms. International Journal of Science and Research (IJSR) 4: 227-229.

[3]. Sengar S (2014) Maximum Power Point Tracking Algorithms for Photovoltaic System. International Review of Applied Engineering Research 4: 147-154.

[4]. Chetan SS (2013) Solar Photovoltaic Technology \& Systems: A Manual for Technicians, Trainers \& Engineers.(2ndedn), PHI Learning Pvt Ltd.

[5]. Mukund RP (1999) Wind and Solar Power Systems: Design, Analysis, and Operation. (2ndedn), CRC Press Taylor \& Francis Group. Conclusions 